\title{
Human Influences on Water Quality in Great Lakes Coastal Wetlands
}

\author{
John A. Morrice $\cdot$ Nicholas P. Danz $\cdot$ Ronald R. Regal $\cdot$ John R. Kelly \\ Gerald J. Niemi - Euan D. Reavie - Tom Hollenhorst - Richard P. Axler • \\ Anett S. Trebitz · Anne M. Cotter · Gregory S. Peterson
}

Published online: 21 December 2007

(C) Springer Science+Business Media, LLC 2007

\begin{abstract}
A better understanding of relationships between human activities and water chemistry is needed to identify and manage sources of anthropogenic stress in Great Lakes coastal wetlands. The objective of the study described in this article was to characterize relationships between water chemistry and multiple classes of human activity (agriculture, population and development, point source pollution, and atmospheric deposition). We also evaluated the influence of geomorphology and biogeographic factors on stressor-water quality relationships. We collected water chemistry data from 98 coastal wetlands
\end{abstract}

J. A. Morrice $(\bowtie) \cdot$ J. R. Kelly · A. S. Trebitz ·

A. M. Cotter - G. S. Peterson

Mid-Continent Ecology Division, National Health and

Environmental Effects Research Laboratory, Office of Research and Development, U.S. Environmental Protection Agency, 6201

Congdon Boulevard, Duluth, MN 55804, USA

e-mail: morrice.john@epa.gov

N. P. Danz · G. J. Niemi · E. D. Reavie - T. Hollenhorst ·

R. P. Axler

Center for Water and the Environment, Natural Resources

Research Institute, University of Minnesota Duluth, 5013 Miller

Trunk Highway, Duluth, MN 55811, USA

R. R. Regal

Department of Mathematics and Statistics, University of

Minnesota Duluth, 10 University Drive, Duluth, MN 55811, USA

G. J. Niemi

Department of Biology, University of Minnesota Duluth, 10

University Drive, Duluth, MN 55811, USA

\section{E. D. Reavie}

Center for Water and the Environment, Natural Resources Research Institute, University of Minnesota Duluth, 1900 East Camp Street, Ely, MN 55731, USA distributed along the United States shoreline of the Laurentian Great Lakes and GIS-based stressor data from the associated drainage basin to examine stressor-water quality relationships. The sampling captured broad ranges (1.5-2 orders of magnitude) in total phosphorus (TP), total nitrogen (TN), dissolved inorganic nitrogen (DIN), total suspended solids (TSS), chlorophyll $a$ (Chl $a$ ), and chloride; concentrations were strongly correlated with stressor metrics. Hierarchical partitioning and all-subsets regression analyses were used to evaluate the independent influence of different stressor classes on water quality and to identify best predictive models. Results showed that all categories of stress influenced water quality and that the relative influence of different classes of disturbance varied among water quality parameters. Chloride exhibited the strongest relationships with stressors followed in order by TN, Chl $a$, TP, TSS, and DIN. In general, coarse scale classification of wetlands by morphology (three wetland classes: riverine, protected, open coastal) and biogeography (two ecoprovinces: Eastern Broadleaf Forest [EBF] and Laurentian Mixed Forest [LMF]) did not improve predictive models. This study provides strong evidence of the link between water chemistry and human stress in Great Lakes coastal wetlands and can be used to inform management efforts to improve water quality in Great Lakes coastal ecosystems.

Keywords Water quality - Nutrients - Anthropogenic stress - Landscape · Coastal wetlands · Great Lakes · Biogeography $\cdot$ Hydrogeomorphic classification

\section{Introduction}

Water quality in an aquatic ecosystem is determined by many physical and biological factors. Streams, lakes, and 
inland wetlands are interactive components of watersheds, and physical and chemical conditions of these ecosystems reflect the land use patterns and physical characteristics of the landscapes in which they are embedded. In contrast, the coastal ecosystems of large bodies of water are located at the margins of watersheds, and water quality in coastal ecosystems may reflect linkages to both landward and offshore environments. Although coastal ecosystems may not be as strongly linked to landscapes as systems that are embedded in watersheds, coastal zones are among the most densely populated regions on earth and impairment of coastal receiving waters is a widespread problem (Nixon 1995; U.S. EPA 2001).

There is a growing awareness among managers and researchers that the ecological condition of coastal ecosystems in the Laurentian Great Lakes is tightly linked to land use practices in adjacent watersheds (U.S. and Canada 1997). Coastal wetlands of the Great Lakes are situated at the interface between watershed and lake, and are particularly vulnerable to land-based stressors. A defining feature of Great Lakes coastal wetlands is that they have a hydrologic connection to their adjacent lake and that water levels change in response to changes in lake level (Keough and others 1999). Great Lakes coastal wetlands are a hydrologically diverse population of ecosystems ranging from wetlands at the mouths of large rivers to systems with no surface water input. While there are Great Lakes coastal wetlands that receive all of their hydrologic inputs from lake water via seiche driven exchange, it is more common that wetland water is a mixture of lake water and tributary or groundwater from the wetland's watershed (Trebitz and others 2002).

Researchers have established relationships between land use patterns and water quality in Great Lakes coastal wetlands at regional (Crosbie and Chow-Fraser 1999; Uzarski and others 2004) and local (Morrice and others 2008) scales. Crosbie and Chow-Fraser (1999) and Morrice and others (2008) found correlations between proportions of agricultural land use and water chemistry, and Uzarski and others (2004) found that some water quality parameters were correlated with agricultural land use and others with proportions of urban land. The Laurentian Great Lakes basin exhibits broad ranges in the intensity of agriculture, urban and residential development, and atmospheric deposition of ions and particulates (Danz and others 2007), all of which are anthropogenic sources of stress that can impact water quality in aquatic ecosystems (Carpenter and others 1998). A combination of these stressors frequently operates in Great Lakes watersheds, complicating the task of diagnosing the causes of water quality impairment.

The goal of this study was to evaluate the relative influences of different types of anthropogenic activities on water quality in coastal wetlands of the Great Lakes basin. We used a geographic information system (GIS) to develop metrics related to agricultural practices, human population distribution, point source pollution, and atmospheric deposition. We analyzed water quality data from 98 coastal wetlands selected to represent ranges in each stressor class across the entire United States coastline of the Great Lakes. We used hierarchical partitioning and all-subsets regression to determine the independent influence of different stressor categories on water chemistry parameters.

We also evaluated the extent to which relationships between anthropogenic stressors and water quality were organized by biogeographic factors and by features of wetland geomorphology related to hydrology. There are broad gradients within the Laurentian Great Lakes basin in climatologic and geologic factors that can influence the chemistry and biology of aquatic ecosystems (Omernick and Gallant 1988; Keys and Carpenter 1995). In this article we test whether categorizing wetlands by ecoprovince (Keys and Carpenter 1995) improves the resolution of models relating water quality to anthropogenic stressors. Recent classification schemes for Great Lakes coastal wetlands have focused on features of wetland geomorphology and hydrology (Keough and others 1999; Albert and others 2005). These schemes propose that sources and chemistry of wetland water are a function of the relative strength of hydrologic linkages to lake and watershed and that they vary predictably among hydrogeomorphic classes. We compared stressor-water quality relationships in three hydrogeomorphic classes of coastal wetlands. We expected that landbased anthropogenic activities would be more strongly expressed in the water quality of the geomorphic classes of wetlands with the strongest connections to their watersheds (riverine and protected wetlands) than in wetlands that are most strongly connected to lakes (open coastal wetlands).

\section{Methods}

\section{Site Selection}

We selected 98 wetlands along the U.S. shoreline of the Laurentian Great Lakes from two ecoprovinces (Eastern Broadleaf Forest and Laurentian Mixed Forest) (Bailey 1989) in three hydrogeomorphic classes (riverine, protected, and open coastal) (Table 1; Fig. 1). A goal of our sampling design was to select sites to span existing gradients of anthropogenic stress in each hydrogeomorphic class in both ecoregions. Wetlands were identified and hydrogeomorphic class was determined by analyzing digitized topographic maps and referencing available wetland inventories (Herdendorff and others 1981). For the purpose of hydrologic delineation and stressor characterization, the study area was divided into 762 segment-sheds, defined as the hydrologic contributing areas of segments of shoreline 
Table 1 Number of sampled wetlands

\begin{tabular}{|c|c|c|c|c|c|c|c|}
\hline \multirow[t]{2}{*}{ Lake } & \multicolumn{3}{|c|}{ Laurentian Mixed Forest } & \multicolumn{3}{|c|}{ Eastern Broadleaf Forest } & \multirow[t]{2}{*}{ Total } \\
\hline & Coastal wetlands & Protected wetlands & Riverine wetlands & Coastal wetlands & Protected wetlands & Riverine wetlands & \\
\hline Erie & - & - & - & 1 & 8 & 5 & 14 \\
\hline Huron & 4 & 5 & 1 & 3 & 3 & 2 & 18 \\
\hline Michigan & 5 & 5 & 9 & - & 2 & 10 & 31 \\
\hline Ontario & 1 & 1 & 1 & 3 & 4 & 6 & 16 \\
\hline Superior & 2 & 10 & 7 & - & - & - & 19 \\
\hline Total & 12 & 21 & 18 & 7 & 17 & 23 & 98 \\
\hline
\end{tabular}

Fig. 1 Study area

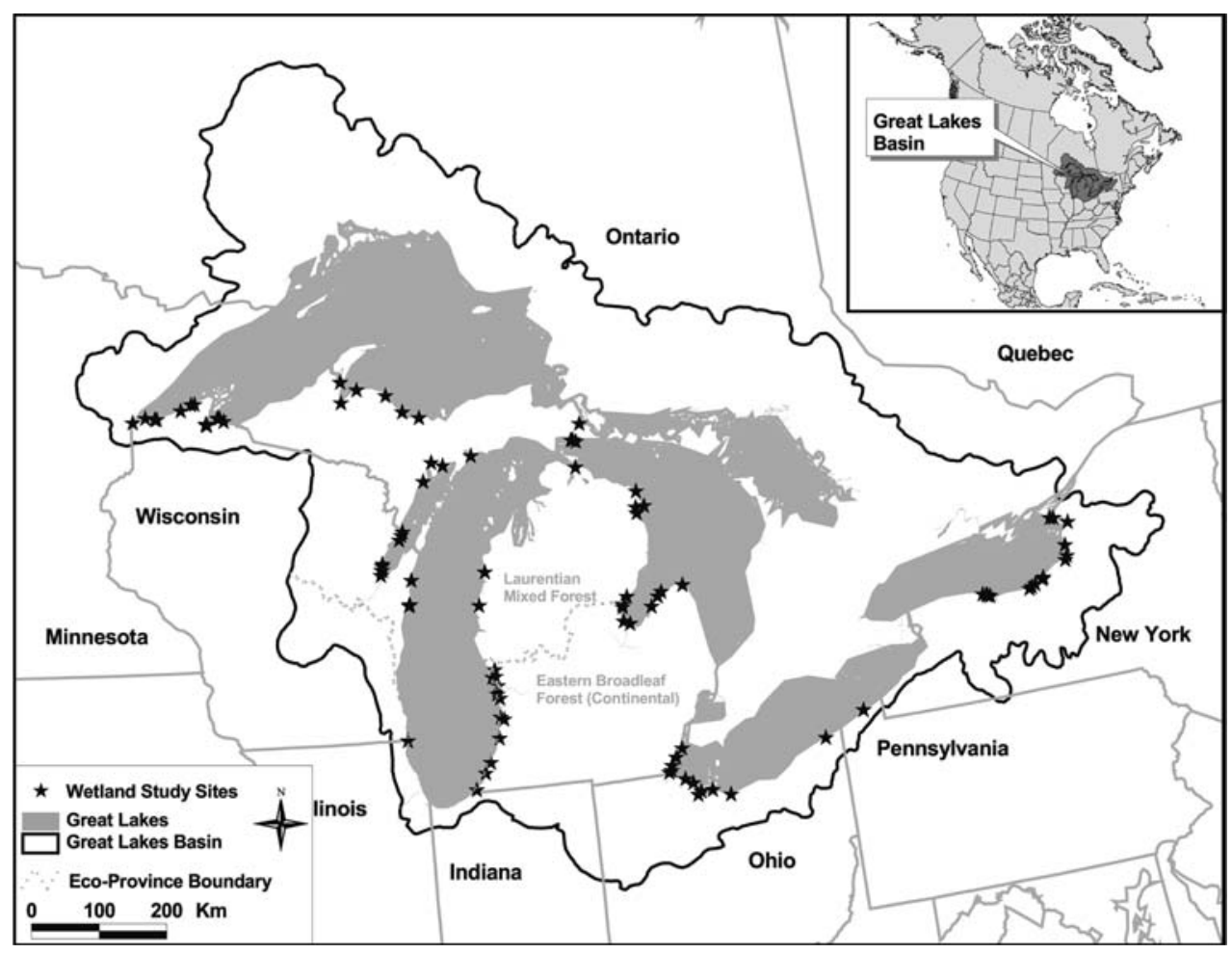

with boundaries at the mid-points between consecutive streams of second order or higher (Danz and others 2005). For each segment-shed, 207 variables that represented anthropogenic activities, geology, and climate were taken from web-based public databases and compiled in a GIS. Multivariate analysis of the data was used to partition the 762 segment-sheds into clusters with similar stressor regimes. Study sites were randomly selected from each cluster. The decision to sample or reject a selected site was based on access (Danz and others 2005).

\section{Field Methods}

Sites were sampled between June and August of 2002 and 2003. Between two and seven water samples were collected from each wetland. The number of samples taken was proportional to the wetland size. Samples were collected at locations off the thalweg and efforts were made to avoid disturbing macrophyes or suspending sediments. Samples were collected with a bucket and transferred to a 4-L cubitainer. Samples were placed on ice and processed within 12 hours of collection.

Sample Processing and Analysis

Samples were analyzed for total nitrogen (TN), total phosphorus (TP), ammonium nitrogen $\left(\mathrm{NH}_{4}^{+}-\mathrm{N}\right)$, nitrate nitrogen $\left(\mathrm{NO}_{3}^{-}-\mathrm{N}+\mathrm{NO}_{2}^{-}-\mathrm{N}\right)$, hereafter referred to collectively as $\mathrm{NO}_{3}^{-}-\mathrm{N}$, chlorophyll $a(\mathrm{Chl} a)$, chloride $(\mathrm{Cl})$, total suspended solids (TSS), and dissolved organic carbon (DOC). Processing involved filtration and preservation: 
nitrate, ammonium, Chloride, and DOC sub-samples were filtered through Millipore $0.45 \mu \mathrm{m}$ membranes. Samples for nitrate and ammonium were frozen and samples for chloride and DOC were refrigerated until analysis; TSS and Chl $a$ filtrations used Whatman GF/C glass fiber filters; raw water was frozen for TP and TN analyses. Pre-weighed TSS filters were immediately air-dried and Chl $a$ filters were wet-frozen. TSS was determined gravimetrically after drying filters at $105^{\circ} \mathrm{C}$. Chl $a$ was extracted with acetone and analyzed by fluorometry (Welschemeyer 1994). $\mathrm{NH}_{4}^{+}-\mathrm{N}$ and $\mathrm{NO}_{3}^{-}-\mathrm{N}$ were analyzed following standard methods (U.S. EPA 1983). Dissolved inorganic nitrogen (DIN) was obtained by summing $\mathrm{NH}_{4}^{+}-\mathrm{N}$ and $\mathrm{NO}_{3}^{-}-\mathrm{N}$. Samples for $\mathrm{TN}$ and TP were digested using persulfate and analyzed as $\mathrm{NO}_{3}^{-} \mathrm{N}$ and soluble reactive phosphorus (U.S. EPA 1993). Chloride was analyzed using ion chromatography (U.S. EPA 1991). DOC was analyzed using catalytic oxidation infrared detection.

\section{Data Analysis}

Water chemistry variables ( $y$ 's) were computed as means per wetland. Wetland means were weighted in the regressions by the inverse of the variance for each wetland $i$ according to the usual variance components formula for nested designs (Sokal and Rohlf 1981):

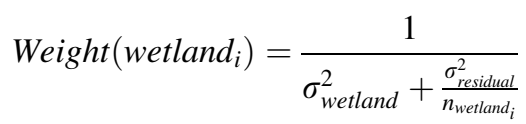

Weights were used to account for different sampling intensity ( $n$ subsamples) between wetlands. Thus, wetlands with greater sampling intensity and smaller variances received greater weights.

Stress variables ( $x$ 's) represented four major types of stress in the Great Lakes basin: agriculture, atmospheric deposition, human population, and point source pollution. Danz and others (2007) describe the development of these stress gradients in detail. Briefly, Danz and others (2007) carried out separate principal components analyses for the four categories of stress data and interpreted the first principal component (PC) within each category as a metric of a particular type of stress (Table 2). Stress data and PCs were computed for segment-sheds; wetlands were assigned stress data that corresponded to the segment-shed they occurred in to reflect the premise that environmental conditions in coastal wetlands are influenced by human activities in coastal watersheds.

Proportions of land cover have been frequently used to evaluate the influence of anthropogenic stressors on aquatic ecosystems, but lack of independence among proportions of different land use classes can make interpretation of results difficult (King and others 2005). We avoided these analytical limitations by using data related to stressor density (point source pollution and human population data) or aerial rate of application (agricultural chemical and atmospheric deposition data) to construct the PCs for each category of anthropogenic stress, rather than using proportions of landcover. To facilitate comparisons with other studies, we compared agriculture PC1 and land cover proportions of agriculture as predictors of water quality parameters.

In a multiple-regression context, statistical modeling often has two subtly different goals: (1) to understand the causal influence of the $x$-variables on the $y$-variable and (2) to develop a single "best" predictive model (MacNally 2000). Model selection techniques (e.g., stepwise regression) are often used to satisfy both objectives, although single models are not the most effective way of identifying important causal variables due to collinearity among the predictors (King and others 2005). MacNally (2002) suggested that strong explanatory conclusions could result from a combination of approaches that addressed both modeling goals. We used hierarchical partitioning (HP) (Chevan and Sutherland 1991; Christensen 1992) to evaluate the independent influence of the four stressors on each water chemistry variable while alleviating collinearity among the stressors (Table 3). In HP the goal is to compare the influence of each predictor variable on a response over a hierarchy of all possible $2^{n}$ models for $n$ predictors instead of identifying a single best model (MacNally 2000, 2002). The importance of each predictor is estimated by averaging the increase in model fit over all models in which a predictor occurs. In other words, HP asks: what is the average effect of including a predictor in all first-order models (i.e., those models that include the other

Table 2 Interpretation of first principal components from PCAs for four stress categories (see Danz and others 2007)

\begin{tabular}{|c|c|c|c|}
\hline Stress category & $n$ variables & $\%$ variance & Interpretation \\
\hline Agriculture & 21 & 73 & $\begin{array}{l}\text { gradient from low }(-) \text { to high }(+) \text { export of applied agricultural fertilizers } \\
\text { and pesticides }\end{array}$ \\
\hline Atmospheric deposition & 11 & 75 & gradient from low $(-)$ to high $(+)$ amounts of atmospheric deposition of ions \\
\hline Human population & 14 & 33 & $\begin{array}{l}\text { gradient from low }(-) \text { to high }(+) \text { densities of human population, development, } \\
\text { and roads }\end{array}$ \\
\hline Point source pollution & 79 & 41 & $\begin{array}{l}\text { gradient from low }(-) \text { to high }(+) \text { density of facilities discharging pollutants } \\
\text { into wastewater }\end{array}$ \\
\hline
\end{tabular}


Table 3 Pearson correlation matrix for water chemistry and stress variables

\begin{tabular}{|c|c|c|c|c|c|c|c|c|c|c|c|c|}
\hline Variable & $\mathrm{TN}$ & DIN & $\mathrm{TP}$ & TSS & DOC & $\begin{array}{l}\text { Chl } \\
a\end{array}$ & $\mathrm{Cl}^{-}$ & Agriculture & $\begin{array}{l}\text { Atm. } \\
\text { dep. }\end{array}$ & $\begin{array}{l}\text { Human } \\
\text { pop. }\end{array}$ & $\begin{array}{l}\text { Point } \\
\text { source }\end{array}$ & $\begin{array}{l}\text { Ag. } \% \\
\text { Land } \\
\text { Cover }\end{array}$ \\
\hline $\mathrm{TN}$ & 1 & & & & & & & & & & & \\
\hline DIN & 0.47 & 1 & & & & & & & & & & \\
\hline $\mathrm{TP}$ & 0.74 & 0.23 & 1 & & & & & & & & & \\
\hline TSS & 0.58 & 0.24 & 0.75 & 1 & & & & & & & & \\
\hline DOC & 0.44 & -0.29 & 0.31 & 0.11 & 1 & & & & & & & \\
\hline Chl $a$ & 0.69 & 0.19 & 0.77 & 0.77 & 0.25 & 1 & & & & & & \\
\hline $\mathrm{Cl}^{-}$ & 0.51 & 0.33 & 0.41 & 0.29 & -0.09 & 0.40 & 1 & & & & & \\
\hline Agriculture & 0.62 & 0.38 & 0.50 & 0.37 & -0.04 & 0.50 & 0.75 & 1 & & & & \\
\hline Atm. dep. & 0.32 & 0.18 & 0.29 & 0.05 & -0.10 & 0.22 & 0.55 & 0.71 & 1 & & & \\
\hline Human pop. & 0.48 & 0.23 & 0.50 & 0.24 & 0.05 & 0.39 & 0.63 & 0.69 & 0.56 & 1 & & \\
\hline Point source & 0.56 & 0.28 & 0.46 & 0.37 & 0.17 & 0.59 & 0.46 & 0.51 & 0.21 & 0.47 & 1 & \\
\hline $\begin{array}{l}\text { Ag. } \% \text { land } \\
\text { cover }\end{array}$ & 0.45 & 0.43 & 0.51 & 0.49 & -0.19 & 0.49 & 0.48 & 0.61 & 0.39 & 0.34 & 0.29 & 1 \\
\hline
\end{tabular}

Correlations with $r \geq 10.20 \mid$ are significant at $\alpha=0.05$

predictors individually), all second-order models (i.e., those that include all pairs of the other predictors), and all higherorder models? If predictor $U$ has strong independent effects, then a first-order model that includes $U$ with $W$ should yield a substantially better fit than a model with $W$ alone. Similarly, a second-order model with $U, W$, and $V$ should yield a substantially better fit than a model with only $W$ and $V$. It is the averaging of the increase in model fit for each predictor variable across the hierarchy of models that minimizes multicollinearity problems that are effectively ignored using any single-model-seeking technique (McNally 2000, 2002) and allows for the identification of the variables whose independent - not partial — correlation with the dependent variable may be important. Conceptually, HP can be used in a variety of multiple regression settings (e.g., normal linear regression, logistic, Poisson) with any goodness of fit measure (e.g., $r^{2}$, log-likelihood). Our HP analyses were carried out with the hier.part package (Walsh and MacNally 2004) in the statistical software R version 2.0.1 (R Development Core Team 2004) using multiple linear regression models and $r^{2}$ as a measure of model fit. Significance of the independent contribution to variance $(I)$ for the four predictors was assessed using Z-scores from a comparison of the observed Is to Is resulting from 100 permutations on randomized data (MacNally 2002).

We used all-subsets regression in SAS PROC GLM (SAS Institute 2004) to develop "best" predictive models for each water chemistry variable using the four stress variables. Best models were chosen with Akaike's Information Criterion. Further, we investigated the influence of ecoprovince and wetland hydrogeomorphic type above and beyond the significant stressors by adding class variables for these effects ( 2 levels for ecoprovince, 3 levels for wetland type) and testing for their significance in GLM. We evaluated the main effects of ecoprovince and wetland type and all two-way interactions of the class variables with the retained stress variables, and the ecoprovince $x$ wetland type interaction. Interactions were removed when not statistically significant. We computed least-squares means for the ecoprovince and wetland type main effect and used Tukey's procedure to test all pairwise differences among class levels. Least-square means for a class effect are means adjusted for all other variables in the model (SAS Institute 2004). In addition, the analysis was repeated replacing ecoprovince with lake as a factor in all models. Differences in stressor-water quality relationships between sub-populations would be expressed as differences in $y$-intercepts, where biogeography or morphology would be significant factors in a model. For example, if background concentrations of a water quality constituent in coastal wetlands differ between ecoregions, the stressor-water quality relationships of coastal wetlands in the two ecoregions would have different $y$-intercepts. Significant interactions between stressor metrics and biogeography or morphology in multiple regressions would indicate that the stressor-water quality relationships of subpopulations have different slopes. This might occur, for example, if a water chemistry parameter increased with stress more steeply for one wetland type than the others.

\section{Results}

Relationships of Study Sites to Basin-Wide Stressor Gradients

Ranges in scores of study sites for agriculture PC1 and atmospheric deposition PC1 were above $85 \%$ of basin-wide 
ranges. We were unable to select sites in the upper ranges for point source pollution PC1 or human population PC1 because there were no coastal wetlands in these predominantly urban segment-sheds. The broad ranges in stressor regime among the sampled wetlands corresponded to broad gradients in water quality, with water quality parameters varying over 1.5 to 2 orders of magnitude (Table 4).

\section{Relationships Between WQ and Stressor Gradients}

Agriculture PC1 was significantly correlated $(p<0.05)$ with concentrations of TP, TN, DIN, Chl $a$, TSS, and $\mathrm{Cl}^{-}$ (Table 3). Relationships between water quality variables and agriculture PC1 were similar in strength to relationships between water quality variables and the proportion of cultivated land in segment-sheds (Table 3). Several water quality parameters were strongly correlated with more than one PC (Table 3). TN, for example, exhibited strong relationships with agriculture PC1, human population PC1, and point source pollution PC1.

\section{Hierarchical Partitioning}

Both agriculture PC1 and point source pollution PC1 explained significant portions of the variance in concentrations of all water quality parameters except for DOC, which was not significantly related to any of the categories of anthropogenic stress (Fig. 2). Human population PC1 and atmospheric deposition PC1 were also significant factors explaining variance of several water quality parameters. The independent influence of different categories of stress on water chemistry was not consistent across water quality parameters. Agriculture PC1 was the strongest factor influencing TN, DIN, TSS and chloride, explaining $23 \%, 12 \%, 11 \%$, and $26 \%$ of their respective variances. Human population PC1 was the strongest

Table 4 Grand mean and range of water quality variables for sampled wetlands $(n=98)$

\begin{tabular}{lc}
\hline Variable & Mean Concentration (Range) \\
\hline TN $\left(\mu \mathrm{g} * \mathrm{~L}^{-1}\right)$ & $809(121-6717)$ \\
DIN $\left(\mu \mathrm{g} * \mathrm{~L}^{-1}\right)$ & $79(8.0-6241)$ \\
TP $\left(\mu \mathrm{g}^{-1}\right)$ & $38(3.0-405)$ \\
TSS $\left(\mathrm{mg}^{*} \mathrm{~L}^{-1}\right)$ & $7.5(1.1-261)$ \\
DOC* $\left(\mathrm{mg}^{*} \mathrm{~L}^{-1}\right)$ & $7.7(1.9-43.1)$ \\
Chl_a $\left(\mu \mathrm{g}^{*} \mathrm{~L}^{-1}\right)$ & $5.6(0.2-90.5)$ \\
Cl- $\left(\mathrm{mg}^{*} \mathrm{~L}^{-1}\right)$ & $13.7(1.1-121)$ \\
\hline
\end{tabular}

All variables were log-transformed and geometric means calculated. Values reported are back-transformed geometric means

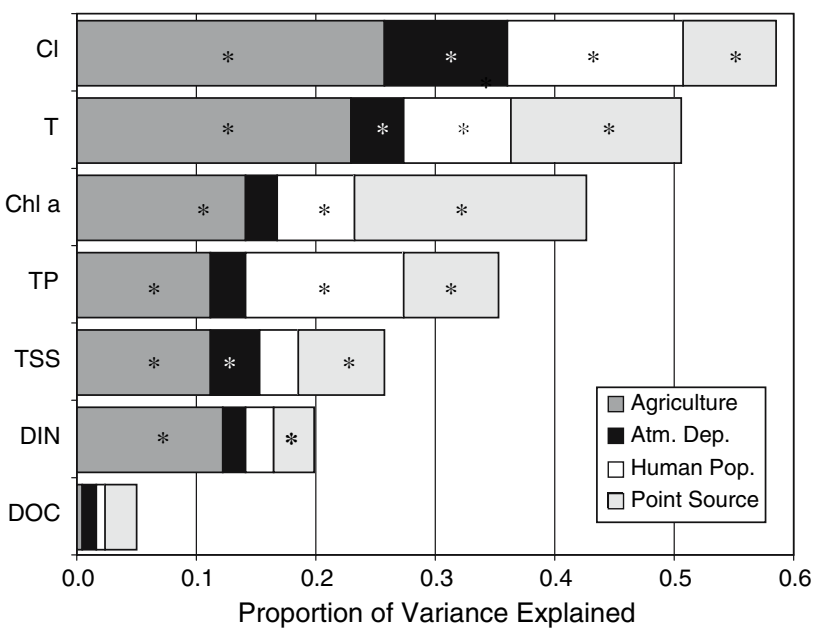

Fig. 2 Results of hierarchical partitioning of water chemistry variables on four anthropogenic stress gradients. Asterisks indicate significant predictors $(\alpha=0.05)$ over the hierarchy of models

independent predictor of TP, explaining $13 \%$ of variance, while point source pollution PC1 was the best independent predictor of Chl $a$, explaining $19 \%$ of variance.

\section{Predictive Models}

While the hierarchical partitioning models identified the independent relative influence of the stressors on water quality variables, the "best" models resulting from allsubsets regression identified significant stressors when considered in combination (Table 5). The two modeling techniques yielded very similar results, with all predictor variables significant in the "best" models also being significant in HP analysis, with the exception of DOC, which was poorly modeled by both techniques.

All of the significant all-subsets regression models included agriculture PC1 and, with the exception of DIN, metrics for one or two additional classes of stress (Table 5). Coefficients for atmospheric deposition PC1 were negative in predictive models for TN and TSS, although individual correlations between atmospheric deposition PC1 and TN and TSS were positive. Atmospheric deposition $\mathrm{PC} 1$, which exhibits a strong west to east gradient, acted as a suppressor variable in these cases, driven by the wetlands of eastern Lake Ontario that had high atmospheric deposition PC1 scores and low TN and TSS concentrations. The strongest predictive model for a water quality parameter was for chloride, where $58 \%$ of variance was explained by agriculture $\mathrm{PC} 1$ and human population PC1.

The only model that was significantly improved by accounting for ecoprovince was TP where, at given levels of agriculture, point source pollution and population related 
Table 5 Best fit regression models relating log-transformed water chemistry variables to the four disturbance variables. Regression equations were generated using all subsets regression analysis. For each dependent variable, the best model was selected using AIC

\begin{tabular}{|c|c|c|}
\hline Variable & Equation & $r^{2}$ \\
\hline $\mathrm{TN}\left(\mu \mathrm{g} * \mathrm{~L}^{-1}\right)$ & $2.50+0.66 *(\mathrm{Ag})-0.23 *($ Atm dep $)+0.38($ Point source $)$ & 0.51 \\
\hline $\operatorname{DIN}\left(\mu \mathrm{g} * \mathrm{~L}^{-1}\right)$ & $1.18+0.98 *(\mathrm{Ag})$ & 0.18 \\
\hline $\mathrm{TP}\left(\mu \mathrm{g} * \mathrm{~L}^{-1}\right)$ & $0.82+0.29 *(\mathrm{Ag})+0.96 *($ Human pop $)+0.42 *($ Point source $)$ & 0.35 \\
\hline $\operatorname{TSS}\left(\mathrm{mg}^{*} \mathrm{~L}^{-1}\right)$ & $0.56+0.95 *(\mathrm{Ag})-0.81 *($ Atm dep $)+0.38 *($ Point source $)$ & 0.26 \\
\hline DOC* $\left(\mathrm{mg}^{*} \mathrm{~L}^{-1}\right)$ & $0.91-1.16^{*}(\mathrm{Ag})+0.36^{*}($ Point source $)$ & 0.05 \\
\hline Chl_a $\left(\mu \mathrm{g} * \mathrm{~L}^{-1}\right)$ & $0.07+0.63 *(\mathrm{Ag})+1.35 *($ Point source $)$ & 0.41 \\
\hline $\mathrm{Cl}-\left(\mathrm{mg} * \mathrm{~L}^{-1}\right)$ & $-0.03+1.14 *(\mathrm{Ag})+0.89 *($ Human population $)$ & 0.58 \\
\hline
\end{tabular}

$* p>0.05$

stress, concentrations were higher in the LMF province than in the EBF province. There were no significant interactions between ecoprovince and stressor variables in any of the models. Categorizing the sampled coastal wetlands by lake significantly improved predictive models for $\mathrm{TN}$, DIN, TSS, and $\mathrm{Cl}^{-}$. At given levels of agriculture, point source pollution and population related stress, concentrations of TN, DIN and TSS were higher in Lake Erie wetlands than in other lakes and $\mathrm{Cl}^{-}$concentrations were higher in Lake Huron. There were no significant interactions between lake and stressor variables. This study included 19 open coastal wetlands. When these systems were omitted from the all-subsets regression analysis, lake was no longer a significant factor in predictive models for $\mathrm{TN}$ or $\mathrm{Cl}^{-}$. Lake continued to be a significant factor in predictive models for DIN and TSS, but the $F$-statistics for lake as a predictor variable decreased when open coastal wetlands were omitted from the analyses.

With the exception of DIN, accounting for wetland morphology did not significantly improve the strength of predictive models. At given levels of agriculture, point source pollution and population related stress, open coastal wetlands had higher DIN concentrations than protected wetlands. The only significant interaction between predictor variables was between wetland morphology and point source pollution $\mathrm{PC} 1$ in the model predicting $\mathrm{Chl} a$ concentrations.

\section{Discussion}

There is a growing concern about the decline in ecological condition of Great Lakes Coastal wetlands and poor water quality has been identified as an important factor contributing to wetland impairment (U.S. EPA 1999). Effective efforts to set water quality criteria for coastal wetlands must differentiate between natural variability among wetlands in water chemistry and variability associated with human disturbance. Water chemistry varied widely among the 98 coastal wetlands sampled in this study and mean concentrations generally fell within previously reported ranges for wetlands of the Laurentain Great Lakes (Lougheed and others 2001; McNair and others 2003; Uzarski and others 2005). The Great Lakes basin covers a large area, and the high variability in water chemistry among wetlands is likely a function of gradients in climatological and geologic factors as well as human disturbance (Dillon and Kirchner 1975; Johnson and others 1997; Detenbeck and others 2003). Determining empirical relationships between anthropogenic stressors and water chemistry is an important step toward understanding and accounting for the factors that control water quality in coastal wetlands.

Research has demonstrated that watershed land use practices influence the physical-chemical conditions of receiving waters. Numerous studies have attributed nutrient enrichment in streams to the export of nutrients that have been applied to agricultural lands as fertilizer or manure, and agricultural practices have been linked to nutrient levels in lotic ecosystems of the Great Lakes basin (Dillon and Kirchner 1975; Johnson and others 1997). Our results suggest that, at the basin scale, Great Lakes coastal wetland water quality is strongly and positively related to agricultural practices as expressed by both the proportion of cultivated land and by agriculture PC1, an index of the intensity of agricultural chemical use. A linkage between coastal wetland water chemistry and agricultural land use is consistent with the findings of Crosbie and Chow-Fraser (1999), who reported strong relationships between agricultural land use and an integrated index of nutrient enrichment in coastal wetlands in the Canadian portion of the Great Lakes basin. Morrice and others (2008) described similar relationships in a suite of coastal wetlands in western Lake Superior where concentrations of TP and inorganic forms of nitrogen and phosphorus were positively related to proportions of agricultural land in a wetland's watershed. 
In addition to agriculture, point source discharges, activities related to urban and residential development, and atmospheric deposition can be significant sources of nutrients and other chemicals that impact water quality (Carpenter and others 1998). Broad gradients in agriculture, population and development, point source pollution, and atmospheric deposition are present in the Great Lakes basin (Danz and others 2007). While metrics of these stressors were all significantly correlated, there was considerable variability in the relationships between metrics indicating that the relative contribution of an individual class of stress to the combined anthropogenic stress regime of a wetland varies among sites. For example, at a given level of agricultural activity, the study included sites spanning a broad range in variables related to population density and development. As a result, in evaluating human impacts on coastal wetland water quality, it is necessary to understand the relative influences of different classes of stress on water chemistry. We determined the independent influence of anthropogenic stress related to agriculture, population and development, point source pollution, and atmospheric deposition on water quality in coastal wetlands using hierarchical partitioning and all-subsets regression analysis. Results confirmed that coastal wetland water quality was strongly and positively related to agricultural activity but also revealed that metrics related to other types of anthropogenic activities significantly influenced water chemistry (Fig. 2).

All four classes of disturbance explained significant portions of the variance in chloride concentrations. Anthropogenic sources of chloride include road salt, agricultural chemicals, sewage discharge and atmospheric deposition; chloride concentration has been used as an integrative indicator for human disturbance (Herlihy and others 1998). Chloride was more strongly related to stressor metrics than nitrogen or phosphorus species, a pattern that is similar to the land-use water quality relationships described by Herlihy and others (1998) in a study of streams in the Mid-Atlantic region of the United States. Nutrient concentrations are more strongly influenced by biological and chemical transformations than chloride (Wetzel 1983) and the decreased fidelity of relationships between nutrients and stressor metrics relative to chloride may be due to biogeochemical processing of nitrogen and phosphorus during transport from watershed to wetland and to cycling within wetlands.

The linkage between agricultural land use and concentrations of nitrogen species in stream water has been well documented (Johnson and others 1997; Jordon and others 1997; Dodds and Oakes 2006), and agricultural chemical usage proved to be the best predictor of TN and DIN in the coastal wetlands sampled in this study. Our results suggest that point source discharges, which can be a significant source of nitrogen pollution in streams (Carpenter and others 1998; Paul and Meyer 2001), are also important sources of TN and DIN to coastal wetlands. TN was more strongly related to anthropogenic stressors than DIN. This difference may reflect biological cycling of inorganic nitrogen, as ammonium and nitrate are relatively labile components of TN and internal biogeochemical cycling can significantly alter inorganic nitrogen concentrations in coastal wetlands (Morrice and others 2004; Krieger 2003).

There was higher variability in models predicting TP than in models for TN, a pattern that has been documented in streams ecosystems (Johnson and others 1997; Jordon and others 1997; Dodds and Oakes 2006). Regional scale studies of streams in the Great Lakes basin have found that phosphorus dynamics are regulated by geologic factors (Dillon and Kirchner 1975; Detenbeck and others 2003), where export of $\mathrm{P}$ from watersheds with sedimentary rocks is greater than export from watersheds with igneous bedrock. Jordan and others (1997) observed that TP was most strongly associated with suspended particles in streams of the Chesapeake Bay watershed and concluded that a large pool of phosphorus was adsorbed to and transported with sediment. TP was highly correlated with TSS in the coastal wetlands sampled in this study and it is likely that phosphorus concentrations are influenced by factors controlling erosion and sediment transport. In contrast with streams, where hydraulic residence times are short and primary production is typically dominated by periphyton, coastal wetlands can have long residence times that allow for significant planktonic primary production (McNair and Chow-Fraser 2003). TP was also strongly correlated with water column concentrations of $\mathrm{Chl} a$, suggesting that phytoplankton is another important pool of phosphorus in coastal wetlands. Our metric of population density and development was the best predictor of coastal wetland TP concentrations followed by the metrics of point source discharges and agricultural activities. Urban land use (Osborne and Wiley 1988; Paul and Meyer 2001), point source discharges (Paul and Meyer 2001), and agricultural land use (Dillon and Kirchner 1975; Buck and others 2004) have all been linked to phosphorus enrichment in stream ecosystems.

Together the results of hierarchical partitioning analysis and all-subsets regression suggest that water quality in Great Lakes costal wetlands varies in response to a suite of anthropogenic stresses. In contrast, Crosbie and ChowFraser (1999), Uzarski and others (2004), and Morrice and others (2008) all found that variability in water quality parameters was significantly related to a single class of stress. Others have demonstrated that water quality in streams (Johnson and others 1997; King and others 2005) varies in response to the combined influence of multiple stressors. In a study of landscape influences on stream 
water chemistry in the watershed of Saginaw Bay on Lake Huron, Johnson and others (1997) found that, in addition to row crop agriculture, proportion of urban land was an important factor explaining variability in water quality. King and others (2005) recognized that the strength of correlations between agriculture and nitrate in streams of the Coastal Plain of Maryland could obscure significant but weaker correlations with other classes of land cover. They used partial correlation analysis to factor out the overriding influence of cropland, and found significant and positive correlations between proportions of developed land and stream nitrate concentrations. In our analysis of relationships between anthropogenic stress and water quality in coastal wetlands, hierarchical partitioning provided a method of accounting for intercorrelation between stressor categories and evaluating the independent influence of a suite of stressors on water quality.

\section{Classification Factors}

More than $40 \%$ of the variability in all parameters was not attributable to anthropogenic stressors. While many of the stressor water chemistry relationships that we observed were strong, variability in these relationships would need to be reduced before they could be used to guide management decisions. We included descriptors of biogeography and wetland morphology as factors in our sampling design in an effort to identify sub-populations of Great Lakes coastal wetlands that differed in the relationship between anthropogenic stressors and water quality. Our goal in identifying and accounting for these differences was to decrease uncertainty in predictive models that relate water chemistry to stressor regime and increase confidence in our ability to set expectations for water quality that protect coastal wetlands.

Our sampling was designed to test whether relationships between anthropogenic activities and water quality differed between the two ecoprovinces containing the Great Lakes. Overall, predictive models were not improved by this coarse level of geographic classification and the geographic distribution of sampled wetlands was not sufficient to allow us to perform a post hoc evaluation of the efficacy of higher resolution biogeographic classification schemes, such as level III ecoregions (Omernick and Gallant 1986). Grouping coastal wetlands by lake significantly improved models for TN, DIN, TSS, but this result appears to have been largely driven by the influences of a single region (Western Lake Erie) and a single geomorphic class of wetlands (open coastal wetlands). Composition of water in open coastal wetlands, a class of wetland characterized by strong wetland-lake hydrologic linkages, can be dominated by lake water (Keough and others 1999; Albert and others
2005), which would diminish the influence of the surrounding landscape on wetland water chemistry. When we omitted open coastal wetlands from the analysis of relationships between land use and water quality as Lougheed and others (2001) did for Canadian wetlands, the role of lake as a factor in predictive models was diminished. These results suggest that the influence of lake in our predictive models is related to hydrologic exchange between lake and wetland in open coastal wetlands, rather than biogeographic factors that influence linkages between wetland and watershed.

The coastal wetlands sampled included open coastal wetlands, protected wetlands, and riverine wetlands as determined from aerial photographs. Conceptual models of coastal wetland ecosystems have emphasized the importance of the differences in hydrology implied in geomorphic classification (Keough and others 1999; Albert and others 2005). Among geomorphic classes, riverine wetlands are assumed to be most strongly connected to their watersheds with open coastal wetlands having the weakest connections. We had expected that the expression of watershed characteristics in water quality would be strongest in the wetlands with the strongest hydrologic connections to their watersheds but did not find this. The lack of a strong effect of wetland morphology on relationships between water quality and landscape scale stressor data was similar to the results of Crosbie and Chow-Fraser (1999), who found that accounting for wetland morphology did not improve relationships between a water quality index and land use data.

Our results suggest that either hydrogeomorphic differences among wetlands do not influence the expression of watershed characteristics in coastal wetland water quality, or more likely, that existing classification schemes do not describe the specific elements of wetland hydrology that organize relationships of water quality to watershed characteristics. In this study, tributaries to riverine wetlands ranged in size from second order streams with no visible flow to sixth-order rivers. Trebitz and others (2002) observed similar variations in strength of hydrologic linkages to watershed and lake within morphologic classes in a group of coastal wetlands in western Lake Superior. Higher resolution geomorphic classification schemes (e.g., Albert and others 2005) may better capture differences among wetlands in the hydrologic factors that regulate fluxes of materials from watershed to wetland. Data on the hydrologic linkages of coastal wetlands to neighboring ecosystems, including tributary discharge, seiche displacement volume, and geochemical characterizations of lake and tributary waters (Trebitz and others 2002) is needed to better evaluate the relationship between hydrogeomorphic class and water quality in Great Lakes coastal wetlands. 


\section{Conclusions}

The objectives of this study were to examine relationships between watershed-based anthropogenic stressors and water quality in Great Lakes coastal wetlands, and to identify factors, unrelated to human activities, that organize these relationships. There are wide ranges within the Laurentian Great Lakes basin in both the nature and intensity of human activities. Our results indicate that water chemistry in coastal wetlands varies in response to the combined influence of a suite of anthropogenic stressors. In our study of 98 wetlands, metrics related to agricultural practices, human population distribution, point source pollution, and atmospheric deposition were all significant factors in models predicting water chemistry; the relative importance of individual classes of stress varied among water quality parameters. With a few exceptions, accounting for biogeographic and geomorphic factors at relatively coarse scales of resolution did not improve models relating water chemistry to anthropogenic stressors. Our results do not establish a causal relationship between anthropogenic activities and water quality in Great Lakes coastal wetlands, but they do illustrate the importance of considering multiple sources of human disturbance when diagnosing the causes of impairment of coastal ecosystems.

Acknowledgments We thank Matthew Able, Melissa Bertelson, Jason Carlson, Rachel Daw, Tara Jernell, Terri Jicha, Jennifer Kaser, Cory Larson, Amber Seys, Steven Skolasinski, Danny Tanner, Marte Thabes, and Corlis West.for assistance in the field and laboratory. Brian Hill and Don Uzarski provided thoughtful reviews of the manuscript. Danz, Regal, Niemi, Reavie, Hollenhorst, and Axler were supported by a grant from the U.S. Environmental Protection Agency's Science to Achieve Results (STAR) Estuarine and Great Lakes (EaGLe) program through funding to the Great Lakes Environmental Indicators (GLEI) project, U.S. EPA Agreement EPA/R-8286750 and a grant from the National Aeronautics and Space Administration (NAG5-11262). This work has been approved for publication after review by EPA's National Health and Environmental Effects Research laboratory, but the contents do not necessarily reflect the views of the Agency, nor does mention of commercial products constitute endorsement or recommendation for use.

\section{References}

Albert DA, Wilcox DA, Ingram JW, Thompson TA (2005) Hydrogeomorphic classification for Great Lakes coastal wetlands. Journal of Great Lakes Research 31(sup1):129-146

Bailey RG (1989) Explanatory supplement to the ecoregions map of the continents. Environmental Conservation 15(4):307-309

Buck O, Niyogi DK, Townsend CR (2004) Scale-dependence of land use effects on water quality if streams in agricultural catchments. Environmental Pollution 130:287-299

Carpenter SR, Caraco NF, Correll DL, Howarth RW, Sharpley AN, Smith VH (1998) Nonpoint Pollution of surface waters with phosphorus and nitrogen. Ecological Applications 8:559-568

Chevan A, Sutherland M (1991) Hierarchical partitioning. The American Statistician 45:90-96
Christensen R (1992) Comment on Chevan and Sutherland. The American Statistician 46:74

Crosbie B, Chow-Fraser P (1999) Percentage land use in the watershed determinesthe water and sediment quality of 22 marshes in the Great Lakes basin. Canadian Journal of Fisheries and Aquatic Sciences 56:1781-1791

Danz NP, Regal RR, Niemi GJ, Brady VJ, Hollenhorst T, Johnson LB, Host GE, Hanowski JM, Johnston CA, Brown T, Kingston J, Kelly JR (2005) Environmentally stratified sampling design for the development of Great Lakes environmental indicators. Environmental Monitoring and Assessment 102:41-65

Danz NP, Niemi GJ, Regal RR, Hollenhorst T, Johnson LB, Hanowski JM, Axler R, Ciborowski JJH, Hrabik T, Brady VJ, Kelly JR, Morrice JA, Brazner JC, Howe RW, Johnston CA, Host GE (2007) Integrated gradients of anthropogenic stress in the U.S. Great Lakes basin. Environmental Management 39:631-647

Detenbeck NE, Elonen CE, Taylor DL, Anderson LE, Jicha TM, Batterman SL (2003) Effects of hydrogeomorphic region, catchment storage and mature forest on baseflow and snowmelt stream water quality in second-order Lake Superior Basin tributaries. Freshwater Biology 48:912-927

Dillon PJ, Kirchner WB (1975) The effects of geology and land use on the export of phosphorus from watersheds. Water Research 9:135-148

Dodds WK, Oakes RM (2006) Controls on nutrients across a prairie stream watershed: land use and riparian cover effects. Environmental Management. 37:634-646

Herdendorff CE, Hartley SM, Barnes MD (1981) Fish and wildlife resources of the Great Lakes coastal wetlands within the United States, Vol. 3: Lake Erie, U.S. Fish and Wildlife Service, Washington

Herlihy AT, Stoddard JL, Johnson CB (1998) The relationship between stream chemistry and watershed land cover data in the MidAtlantic region, U.S. Water, Air, and Soil Pollution 105:377-386

Johnson LB, Richards C, Host GE, Arthur JW (1997) Landscape influences on water chemistry in Midwestern stream ecosystems. Freshwater Biology 37:193-208

Jordan TE, Correll DL, Weller DE (1997) Effects of agriculture on discharges of nutrients from coastal plain watersheds of Chesapeake Bay. Journal of Environmental Quality 26:836-848

Keough JR, Thompson TA, Guntenspergen GR, Wilcox DA (1999) Hydrogeomorphic factors and ecosystem responses in coastal wetlands of the Great Lakes. Wetlands 19:821-834

Keys JE, Carpenter CA, Hooks SL, Koeneg FG, McNab WH, Russell WE, Smith ML (1995) Ecological Units of the Eastern United States - first approximation. U.S. Dept. of Agriculture, Forest Service

King RS, Baker ME, Whigham DF, Weller DE, Jordan TE, Kazyak PF, Hurd MK (2005) Spatial considerations for linking watershed land cover to ecological indicators in streams. Ecological Applications 15:137-153

Krieger KA (2003) Effectiveness of a coastal wetland in reducing pollution of a Laurentian Great Lake: hydrology, sediment, and nutrients. Wetlands 23:778-791

Lougheed VL, Crosbie B, Chow-Fraser P (2001) Primary determinants of macrophyte community structure in 62 marshes across the Great Lakes basin: latitude, land use, and water quality effects. Canadian Journal of Fisheries and Aquatic Sciences 58:1603-1612

MacNally R (2000) Regression and model-building in conservation biology, biogeography and ecology: The distinction between and - reconciliation of 'predictive' and 'explanatory models. Biodiversity and Conservation 9:655-671

MacNally R (2002) Multiple and inference in ecology and conservation biology: further Comments on indentifying important predictor variables. Biodiversity and Conservation 11:1397-401 
McNair SA, Chow-Fraser P (2003) Change in biomass of benthic and planktonic algae along a disturbance gradient for 24 Great Lakes coastal wetlands. Canadian Journal of Fisheries and Aquatic Sciences 60:676-689

Morrice JA, Kelly JR, Trebitz AS, Cotter AM, Knuth ML (2004) Temporal dynamics of nutrients $(\mathrm{N}$ and $\mathrm{P}$ ) and hydrology in a Lake Superior coastal wetland. Journal of Great Lakes Research 30(sup1):82-96

Morrice JA, Trebitz AS, Kelly JR, Cotter AM, and Knuth ML (2008) Nutrient variability in Lake Superior coastal wetlands: the role of land use and hydrology. Aquatic Ecosystems Health and Management (in press)

Nixon SW (1995) Coastal Marine eutrophication: A definition, social causes, and future concerns. Ophelia 41:199-219

Omernick JM, Gallant AL (1988) Ecoregions of the upper midwest states. U.S. EPA Environmental Research Laboratory, Corvallis, OR, USA

Osborne LL, Wiley MJ (1988) Emperical relationships between land use/cover and stream water quality in an agricultural watershed. Journal of Environmental Management 26:9-27

Paul MJ, Meyer JL (2001) Streams in the urban landscape. Annu Rev Ecol Syst 32:333-365

R Development Core Team (2004) R: A language and environment for statistical computing. R Foundation for Statistical Computing, Vienna, Austria. ISBN 3-900051-07-0, URL http://www.R-project.org

SAS Institute Inc (2004) SAS 9.1.3 Language Reference: Concepts. Cary, NC

Sokal RR, Rohlf FJ (1981) Biometry. W.H. Freeman and Company, New York, NY

Trebitz AS, Morrice JA, Cotter AM (2002) Relative role of lake and tributary in hydrology of Lake Superior coastal wetlands. Journal of Great Lakes Research 28:212-227
U.S., Canada. (1997) State of the Great Lakes 1997. U.S. Environmental Protection Agency and Environment Canada, Chicago and Toronto

U.S. EPA (1983) Methods for chemical analyses of waters and wastes. U.S. Environmental Protection Agency, Cincinnati, OH. EPA-600-/4-79-020

U.S. EPA (1991) The determination of inorganic anions in water by ion chromatography. U.S. Environmental Protection Agency, Cincinnati, OH. Environmental Monitoring Systems Lab. method 300.0

U.S. EPA (1993) Methods for determination of inorganic substances in environmental samples. U.S. Environmental Protection Agency, Cincinnati, OH. EPA/600/R-93/100

U.S. EPA (1999) State of the Great Lakes 1999. U.S. Environmental Protection Agency, Chicago, IL

U.S. EPA (2001) National coastal condition report. U.S. Environmental Protection Agency, Washington, DC, USA

Uzarski DG, Burton TM, Genet JA (2004) Validation and performance of an invertebrate index of biotic integrity for Lakes Huron and Michigan fringing wetlands during a period of lake level decline. Aquatic Ecosystems Health and Management 7:269-288

Uzarski DG, Burton TM, Cooper MJ, Ingram JW, Timmermans STA (2005) Fish habitat use within and across wetland classes in coastal wetlands of the five Great Lakes: development of a fishbased index of biotic integrity. Journal of Great Lakes Research 31(sup1):171-187

Walsh C, MacNally R (2004) hier.part: Hierarchical Partitioning. R package version 1.0

Welschmeyer N (1994) Fluorometric analysis of chlorophyll $a$ in the presence of chlorophyll $\mathrm{b}$ and pheopigments. Limnology and Oceanography 39:1985-1992

Wetzel RG (1983) Limnology. Harcourt Brace Jovanovich, New York 